\title{
JOURNAL OF ASTRONOMY \& EARTH SCIENCES EDUCATION
}

The Journal of Astronomy \& Earth Sciences Education (JAESE) publishes refereed papers that significantly contribute to the scholarly understanding of cutting edge issues across science education. Using a wide range of systematic education research methods including statistical analysis, qualitative inquiry, analytical work, case studies, field research and historical analysis, articles examine significant science education research questions from a broad range of perspectives.

JAESE is an internationally cited, open access journal that is essential reading for academic education researchers and education professionals. Articles may include but are not limited to any contemporary, cutting edge issue describing systematic education research and teaching innovations across the broadly defined Earth \& space sciences education, including the disciplines of astronomy, climatology, energy resource science, environmental science, geology, meteorology, planetary sciences, and oceanography.

Current information for submitting a manuscript is available on our website at www.CluteInstitute.com.

Disclaimer of Liability: No responsibility is assumed by the publisher for injury and/or damages to persons or property as a result of implementing any ideas contained in the material published in the Journal of Astronomy \& Earth Sciences Education. The ideas and theories contained in this publication are those of the authors only.

Copyright: As a condition of publication, the authors must grant The Clute Institute the right to disseminate their manuscript to the widest possible readership in print and electronic format. Authors must also agree to our open access policy.

Open Access Policy: As a condition of publication, the authors must grant The Clute Institute the right to disseminate their manuscript to the widest possible readership in print and electronic format. Authors must also agree to our open access policy, which is to provide immediate open access to our journals on the principle that making research freely available to the public supports a greater global exchange of knowledge. Users are allowed to read, download, copy, distribute, remix, tweak, build upon, print, search, or link the full text of the articles in this journal provided that appropriate credit is given.

Double Blind Peer Reviewed: The Clute Institute, our editors, and members of all editorial teams are committed to objective and fair double-blind peer reviews of submitted manuscripts for journal publication and will evaluate manuscripts for their intellectual content without regard to race, gender, sexual orientation, religious belief, ethnic origin, citizenship, or political philosophy.

For more information about our Code of Publication Ethics, our Plagiarism Policy, our Open Access Policy, and for manuscript guidelines, visit our website at www.CluteInstitute.com. 


\section{JAESE Editorial Board}

As we begin the sixth year, we would like to take this opportunity to publicly recognize the volunteering scholars of the JAESE Editorial Advisory Board and the JAESE Board of Peer Reviewers for their support and efforts during 2018. Without these two groups of dedicated individuals, JAESE would not be the high quality journal that it is today.

\section{Editorial Board}

Andrew Fraknoi, Foothill College, USA

Anthony Lelliott, University of the Witwatersrand, South Africa

C. Aaron Price, Chicago Museum of Science and Industry, United States

David McKinnon, Edith Cowan University, Australia

J. Chris Haynes, Tarelton State University, USA

J. Richard Pomeroy, University of California-Davis, USA

Jadwiga Yaga Richter, University Corporation for Atmospheric Research, USA

Jayashree Ramadas, Tata Institute of Fundamental Research, India

Jill K. Singer, Buffalo State University, USA

Judith S. Lederman, Illinois institute of Technology, USA

Kaatje van der Hoeven Kraft, Whatcom Community College, USA

Kim Kastens, Lamont-Doherty Earth Observatory, USA

Lou Mayo, Goddard Space Flight Center, USA

Meredith L. McAllister, Butler University, USA

Michael Brotherton, University of Wyoming, USA

Michael Fitzgerald, Macquarie University, Australia

Norman G. Lederman, Illinois Institute of Technology, USA

Paulo S. Bretones, Federal University of São Carlos, Brazil

Richard Gelderman, Western Kentucky University, USA

Robert Hollow, CSIRO, Australia

Sanlyn R. Buxner, Univ. of Arizona \& Planetary Science Institute, USA

Sharon P. Schleigh, CAPER Ctr for Astro \& Phys Educ Research, USA

Stephanie J. Slater, CAPER Ctr for Astro \& Phys Educ Research, USA

Tom Foster, University of Southern Illinois, USA

Tomita Akihiko, Wakayama University, Japan

William H Waller, The Galactic Inquirer, USA

\section{Board of Reviewers:}

Alfred Tan, Singapore University, Singapore

Bram Boroson, Clayton State University, USA

C. Renee James, Sam Houston State University, USA

Casey E. Davenport, UNC Charlotte, USA

Christopher Palma, Penn State University, USA

Christopher Sirola, University of Southern Mississippi, USA

Cinzia Cervato, Iowa State University, USA

David Gosselin, University of Nebraska-Lincoln, USA

Matthew R Ganis, Pace University, USA

Urban Eriksson, Kristianstad University, Sweden

Elizabeth Lewis, University of Nebraska-Lincoln, USA

Faruk Soydugan, Canakkale Onsekiz Mart University, Turkey

Georgia Bracey, Southern Illinois University Edwardsville, USA

Greg Bartus, World Science Festival, USA

Hasan Zühtü Okulu, Research Assistant, Turkey

Jacob Noel-Storr, InsightSTEM, USA

Jacqueline Dunn, Midwestern State University, USA 
Julia Plummer, Pennsylvania State University, USA

Kaylan Brae Petrie, Washington State University, USA

Kendra Sibbernsen, Metropolitan Community College, USA

Kim Kastens, Lamont-Doherty Earth Observatory, USA

Kristen Thompson, Davidson College, USA

Lauren Woolsey, Harvard University, USA

Lena Danaia, Charles Sturt University, Australia

Louis Rubbo, Coastal Carolina University, USA

Nicolle Zellner, Albinion University, USA

R.S. Ajin, Geomatics Division, GeoVin Solutions Pvt. Ltd, India

Sarah Katie Guffey, University of Southern Alabama, USA

Shanil Virani, Director, John C. Wells Planetarium, James Madison University, USA

Süleyman Aydin, University of Turkey, Turkey

W. Keith Turner, Link Observatory and Space Science Institute; Carmel Planetarium, USA 


\section{TABLE OF CONTENTS}

31. A Hybrid Hands-On And Computer Simulation Laboratory Activity For The Teaching Of Astronomical Parallax by Ned Ladd (Bucknell University, USA) andKatharyn E. K. Nottis (Bucknell University, USA).

45. Young Children's Ideas About Astronomy by Maureen A. Callanan (University of California, Santa Cruz, USA), Tess A. Shirefley (University of California, Santa Cruz, USA), Claudia L. Castañeda (University of California, Santa Cruz, USA), and Jennifer L. Jipson (California Polytechnic University, San Luis Obispo, USA). 


\title{
EDITOR'S NOTE
}

\section{Yes, Your Methods Section is Boring, But Critically Important}

Timothy F. Slater, University of Wyoming, USA

\begin{abstract}
When judging how important and influential a published article is in a refereed journal, the most important thing one might pay attention to is the evidence-based conclusion and the implications of that conclusion (Slater, 2019). At the same time, another way to judge an article's influence is by looking at how frequently the article is cited, using a tool such as scholar.google.com: The caveat to high citation numbers being a great measure of importance and value is that sometimes a published paper is highly cited simply because its conclusions are incorrect and many authors are capitalizing on the opportunity to correct its mistaken message (Slater, 2018a). A third important component to a great paper is how well the research is situated in the existing literature landscape - the compulsory literature review. The best papers clearly specify the research question's space by stating what is known, what is not known, and why the paper in question fills an important gap in the scholarly community's understanding (Slater, 2018a). What is missing in the most common list of criteria for greatness - conclusions, citations, and situation in the existing literature - is an acknowledgement of the critical importance of the methods section.
\end{abstract}

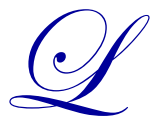
et's face it. The METHODS section of a science paper is usually the most boring to write, and perhaps even more boring to read. The methods section of a scientific paper is where your step-by-step procedure for conducting your study is outlined in great detail. For discipline-based science education papers, the methods section usually starts with a detailed description of who the participants were and how they were selected. This is important as reviewers need to make a judgement about the relative "specialness" of the people being studied. If one were studying 10-year old students' knowledge of astronomy, and all of the students were kids of professional astronomers or lived in a town where everyone spent weekends at the local planetarium, those research-subjects might have a very different knowledge, experience, and motivation base than a sample of students who have never been to a museum in the first place.

As another example of why this is important, studies of science teacher training often struggle with the nature of their sample because researchers use the people in front of them, their own students - a sample of convenience. Convenience samples where education researchers study their own students are subject to inherent bias of the researcher/teacher who often hopes that their own students to do well and learn regardless of any teaching method being employed, which can inadvertently influence how data is collected and how results are interpreted. Any methods section needs to carefully describe who the research-subjects are so that any biases can be considered.

In addition to a detailed description and analysis of who the research subjects are, a full description of any instruments, surveys, tests, or interview scripts needs to be provided for the reader to consider. If you were giving students a rock identification test in geology using English, and most students were weak English readers, one might end up getting a result that more closely measures students reading ability rather than their geology knowledge. Similarly, for multiple-choice tests where the pre-test score is $25 \%$ correct, this could very well be interpreted as students simply guessing at answers rather than revealing anything substantive about their incoming knowledge. In science education studies, it is usually better to use tools developed by someone other than the researcher themselves so that there is no inherent bias in these cases either.

Such an analysis leaves out the critical reason that science education research papers - and all scientific reports for that matter - need an especially strong methods section. The top-line reason for providing an accurate description is that one of the heralded hallmarks of the scientific process is that science is reproducible. Reproducibility is so 
important that there was once even a journal dedicated to the special situation of irreproducible results named The Journal of Irreproducible Results. This perspective is further buoyed up by most of us having memories that every science teacher in every grade we had emphasize the importance of carefully writing out one's procedure in step-bystep detail a science project. If your methods section lacks detail, then not only can readers judge the appropriateness of your approach to answering your question, other researchers would be unable to reproduce your study accurately, which is demanded by the nature of science.

Are methods sections boring? Methods sections are definitely boring. Methods sections should be free from flowery or poetic language and focus on specifying enough detail so that the work can be reproduced and, if necessary, argue for why the chosen research method best fits the problem being tackled (Slater, 2018b). Paying attention to the methods section will definitely improve your chances of successfully navigating the review process.

\section{REFERENCES}

Slater, T. F. (2018a). Improving your argument by identifying a literature gap. Journal of Astronomy \& Earth Sciences Education, 5(1), i-ii.

Slater, T. F. (2018b). Does your article need a methods or methodology sub-section? Journal of Astronomy \& Earth Sciences Education, 5(2), i-ii.

Slater, T. F. (2019). Editor's note: Your article benefits from a compelling conclusion. Journal of Astronomy \& Earth Sciences Education, 6(1), i-v. 


\section{NOTES}

